\title{
Surface-sensitive reflection-mode EXAFS from layered sample systems: the influence of surface and interface roughness
}

\author{
P. Keil and D. Lützenkirchen-Hecht
}

J. Synchrotron Rad. (2009). 16, 443-454

\section{IUCr Journals CRYSTALLOGRAPHY JOURNALS ONLINE}

Copyright (C) International Union of Crystallography

Author(s) of this article may load this reprint on their own web site or institutional repository provided that this cover page is retained. Republication of this article or its storage in electronic databases other than as specified above is not permitted without prior permission in writing from the IUCr.

For further information see http://journals.iucr.org/services/authorrights.html 
Journal of

Synchrotron

Radiation

ISSN 0909-0495

Received 4 February 2009

Accepted 27 April 2009

\section{Surface-sensitive reflection-mode EXAFS from layered sample systems: the influence of surface and interface roughness}

\author{
P. Keil ${ }^{\mathrm{a}}$ and D. Lützenkirchen-Hecht ${ }^{\mathrm{b} *}$

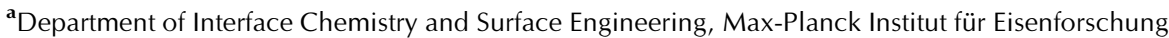 \\ GmbH, Max-Planck-Strasse 1, 40237 Düsseldorf, Germany, and ${ }^{\mathbf{b}}$ Fachbereich C, Physik, Bergische \\ Universität Wuppertal, Gaussstrasse 20, 42097 Wuppertal, Germany. \\ E-mail: dirklh@uni-wuppertal.de
}

\begin{abstract}
The calculation of reflection-mode grazing-incidence X-ray absorption spectra from single surfaces and (multi-)layered systems is studied here. In particular, the influence of the surface and interface roughness was investigated in detail. Simulations of grazing-incidence reflection-mode EXAFS spectra using a simple Fresnel theory neglecting any effect of roughness are compared with the NévotCroce model and the elaborated distorted-wave Born approximation which both include surface and interface roughness. Data are presented for clean gold surfaces, where the strong influence of the surface roughness on the resulting spectra is demonstrated. Furthermore, in the case of layered systems, the influence of both the outer (air or vacuum side) surface roughness and the inner interface roughness on the reflection-mode EXAFS spectra is evaluated. The practical consequences of the observed correlations are discussed, and a quantitative data analysis of a copper sample that was oxidized in ambient air for several months is shown, including the evaluation of specular reflectivity profiles at fixed energy.
\end{abstract}

Keywords: EXAFS; XANES; reflection mode; grazing incidence; surface roughness; DWBA; copper; oxidation; thin films.
C 2009 International Union of Crystallography Printed in Singapore - all rights reserved part $\delta(E)$ and imaginary part $\beta(E)$ of the complex refractive index $n(E)=1-\delta(E)-i \beta(E)$ contribute to the reflectivity fine structure depending on the actual grazing angle and the photon energy $E$. Nevertheless, in the past, short-range-order structural information about surfaces and thin films was derived from reflection-mode EXAFS using the Fresnel theory. In the case of homogeneous samples or thin films with a film thickness larger than the penetration depth of the $\mathrm{X}$-rays into the film, the absorption coefficient can be directly extracted from reflection-mode XAS data by means of a Kramers-Kronig transform, and a conventional EXAFS data analysis yielding coordination numbers, distances and the local disorder around the atom of interest is possible (see, for example, Martens \& Rabe, 1980; Borthen \& Strehblow, 1995; Lützenkirchen-Hecht \& Frahm, 2001; Benzi et al., 2008). However, such an extraction is in general not possible for thin film sample systems with layer thicknesses smaller than the $\mathrm{X}$-ray penetration depth, or in the case of an inhomogeneous distribution of the X-ray absorbing atom within the sample. In those situations the experimental reflection-mode XAS data have to be compared with ( $a b$ initio) model calculations assuming the presence of certain structures and thicknesses of 
the involved surface layers (see, for example, Hecht et al., 1996; Borthen \& Strehblow, 1997; Lützenkirchen-Hecht \& Frahm, 2006; Benzi et al., 2008). Nevertheless, a variation of the grazing angle allows a depth profiling of the materials under investigation similar to X-ray photoelectron spectroscopy (XPS). Compared with XPS, however, there is no need for ultrahigh-vacuum conditions, i.e. solid-liquid interfaces or samples in a reactive gas environment can easily be studied under in situ conditions including time-resolved experiments also (Cortes et al., 1990; Gibson \& Crabb, 1995; Hecht, Borthen \& Strehblow, 1996; Hecht, Frahm \& Strehblow, 1996; Cheong et al., 2001; Lützenkirchen-Hecht \& Frahm, 2005). However, any real surface/interface is generally afflicted with a variety of surface inhomogeneities such as surface roughness and lateral correlations, and the X-ray reflectivity is affected accordingly. In recent years the understanding of X-ray scattering from roughened single surfaces, multilayers and their interfaces has advanced rather far, and it was shown that the adequate treatment of roughness is a very important part of the calculation of the scattered intensities (Névot \& Croce, 1980; Sinha et al., 1988; Hóly \& Baumbach, 1994; de Boer \& Leenaers, 1996; Tolan, 1999). If only vertical roughness features are considered, only one single roughness parameter is required for each surface/interface. Usually the r.m.s.roughness $\sigma$ is used as roughness parameter and in this case the X-ray reflectivity has been formulated a long time ago by extending the Fresnel theory (Parratt, 1954; Névot \& Croce, 1980; Sinha et al., 1988). While the application of the Fresnel theory is restricted to calculations of specular reflectivities, more sophisticated calculation schemes such as the distortedwave Born approximation (DWBA) also allow off-specular reflectivities to be described quantitatively (Sinha et al., 1988; Hóly \& Baumbach, 1994; Tolan, 1999). For this purpose, a complete description of the roughness including lateral roughness features is required. The morphology of surfaces and interfaces which exhibit self-affine roughness can be described using height-height correlation functions like $C(\mathbf{R})=\sigma^{2} \exp \left[(\mathbf{R} / \xi)^{2 h}\right]$, where $\mathbf{R}$ represents the lateral position in the surface plane (Sinha et al., 1988). Thus, a set of three parameters, namely the r.m.s. roughness $\sigma$, the lateral correlation length $\xi$ and the Hurst parameter $h$, is sufficient for the description and characterization of each surface/interface. However, it has to be mentioned that for liquids and interfaces with logarithmic height-height correlation functions more complex models and further parameters have to be used (see, for example, Palasantzas, 1993). While intense calculations and many successful experiments have been performed for specular and non-specular X-ray scattering at fixed photon energies, and thus the influence of the different lateral and vertical roughness features in multilayered samples are well understood, only few studies have been conducted with regard to the influence of roughness on grazing-incidence X-ray absorption spectroscopy, and more specifically on reflectionmode XAS (Borthen \& Strehblow, 1997). To our best knowledge, no systematic investigations have been performed so far, and the existing publications show contradictory results. For example, a systematic decrease of the Fourier-transform amplitudes with increasing roughness was found in a study by Borthen \& Strehblow (1997), while the opposite was the conclusion of a more recent publication (Keil et al., 2005b). Most of the publications up to now have just neglected all roughness effects in the data analysis (e.g. Hecht, Borthen \& Strehblow, 1996; Hecht, Frahm \& Strehblow, 1996; d'Acapito et al., 2002; Cheong et al., 2001; Lützenkirchen-Hecht et al., 2003; Jiang et al., 1991; Jiang \& Crozier, 1997; Luo et al., 2001). Such an approach seems to be reasonable for diluted sample systems, i.e. samples where the reflectivity is determined by the matrix only and the XAFS under investigation is determined by a very small quantity of an atomic species within the matrix (e.g. Jiang et al., 1991; Jiang \& Crozier, 1997; d'Acapito et al., 2002). In this case the effect of roughness could be by far less critical as the refraction index of the matrix is without any structure in the energy region considered, and the thickness of the absorbing layer is smaller than the extinction length of the X-rays. However, for non-diluted sample systems a strong influence of the surface roughness of all of the participating layers to the EXAFS signal can directly be expected from the underlying theory. The interface roughness defines the amplitude of the electric field within the sample at a certain depth from the surface, and therefore also the reflectivity as well as all related signals such as the X-ray fluorescence are thus influenced or even determined by the distribution of the material within the penetration depth of the X-rays within the sample (see, for example, de Boer, 1996). It should be noted here that, for a multiple thin-film sample, the electric fields throughout the material can be found by a recursion relation (Parratt, 1954) or alternatively by a matrix formalism (Born \& Wolf, 1975; Król et al., 1988).

First systematic studies on the influence of the surface roughness on the resulting EXAFS spectra have recently been performed for simple sample systems, and the Fresnel theory was compared with the Névot-Croce model including surface roughness and the DWBA (Keil et al., 2005b). These studies demonstrated the strong influence of the surface roughness on EXAFS amplitudes depending on the actual grazing angle. As a general trend, it was found out that an increasing surface roughness leads to an increase of the intensity of the peaks in the Fourier-transformed data irrespective of the grazing angle (Keil et al., 2005b). For a surface roughness below r.m.s. values of $\sim 5-10 \AA$, only marginal differences to the Fresnel data were observed. This finding explains why it was sufficient to apply the Fresnel reflectivities in many previous studies where films with smooth surfaces were investigated.

Another problem with regard to surface-sensitive XAS experiments is the dramatic change of the X-ray penetration depth in the vicinity of the absorption edge. Thus different depths are probed by the X-rays below, at and above the absorption edge of interest, which complicates especially the analysis of X-ray absorption near-edge spectra measured at grazing incidence. Here we want to investigate in detail the influence of the surface and interface roughness on the resulting reflection-mode XAS spectra. Such an investigation is not only of fundamental interest, owing to its implications 
and drawbacks on reflection-mode EXAFS and XANES experiments, data analysis and interpretation.

\section{Calculation details}

As mentioned in the previous section, both the real $(\delta)$ and the imaginary $(\beta)$ part of the complex refractive index are needed for calculation of the reflectivity as a function of the photon energy. While $\beta$ was directly derived from measured absorption data by $\beta=\mu \lambda / 4 \pi, \lambda$ being the X-ray wavelength, $\delta$ was calculated from $\beta$ by means of a Kramers-Kronig transform (Borthen \& Strehblow, 1995; Cross et al., 1998; Filatova et al., 1999). Making use of these quantities, energy-dependent reflectivity data were calculated for different model systems, as shown below in more detail. Here especially those systems are of particular interest, where the X-ray absorbing atom is present in several layers which is the case for $e$.g. thin oxide or passive layers on metals or semiconductors, corroded or chemically modified surfaces (e.g. Bosio et al., 1988; Cortes et al., 1990; Hecht, Borthen \& Strehblow, 1996; Hecht, Frahm \& Strehblow, 1996; Lützenkirchen-Hecht et al., 2003; Lützenkirchen-Hecht \& Frahm, 2005).

Reflection-mode XAS spectra of layered systems were calculated using a procedure which is given in Fig. 1 as a flow diagram for a layered sample system. In Fig. 1 a thin Au layer on top of a $\mathrm{SiO}_{2}$ substrate is treated as an example. Similar to the calculation of the angle-dependent reflectivity $R(\Theta)$ at a fixed energy (i.e. X-ray reflectometry), the thickness of the surface layer(s) as well as the energy-dependent indices of refraction of both the substrate and the top layer(s) must be known. In the easiest case the latter quantities can be extracted from transmission EXAFS spectra of suited reference compounds. While $\beta(E)$ is correlated with the linear absorption coefficient $\mu(E)$ as already mentioned, $\delta(E)$ can be calculated from $\beta(E)$ by means of a Kramers-Kronig transformation. For a substrate or layers which do not contain the atomic species of the absorption edge under investigation, $\beta(E)$ and $\delta(E)$ do not show any fine structures and these quantities can be directly taken from databases or tabulated values (e.g. Henke et al., 1993). With these energy-dependent complex indices of refraction $n(E)$ of each sublayer and the substrate, the reflectivity spectra were obtained as energydependent reflectivities $R(E, \Theta)$ similar to the calculation of the reflectivity in X-ray reflectometry. For the latter step we have applied several different calculation schemes including the simple Fresnel reflectivity for smooth surfaces according to Parratt (1954). Roughness is accounted for by including roughness features via the addition of the Névot-Croce factor to the reflection and transmission Fresnel coefficients for each layer according to the schemes introduced by Névot \& Croce (1980). Alternatively, the DWBA is also applied, making use of the approach of Sinha et al. (1988) for single interfaces, while for multilayered systems the procedure described by Hóly \& Baumbach (1994) is employed. The calculation procedures are described in detail within the corresponding references and are adapted one by one for the calculation of the reflection-mode EXAFS spectra shown here.
Although the calculation of the X-ray reflectivity based on the Parratt formalism including roughness features (i.e. using the Névot-Croce model) is a well established procedure which works well in most cases, severe limitations occur if the roughness of thin films is similar to the film thickness, like in the case of very thin passive oxide layers on metals or semiconductor surfaces. In the case of the Parratt formalism, the interfaces of the layer stack are usually treated independently. Thus, the density profile $\rho(z)$ obtained by the assumption of independent interfaces is no longer continuous if the roughness at the interfaces is similar to the layer thickness itself. Nevertheless, it is still possible to apply the Parratt formalism for the calculation of the reflectivity making use of arbitrary density profiles as shown, for example, by Tolan (1999). However, the corrections introduced to the Parratt formalism are significant only for incidence angles significantly larger than the critical angle of total reflection $\Theta_{c}$, implying that the Parratt theory is still applicable for grazing angles in the vicinity of the critical angle and below (e.g. Tolan, 1999, chapter 2.4). It is important in this context that reflectionmode XAS measurements are usually performed in the latter angular range, and thus, from a technical point of view, the use of the Névot-Croce model is still justified for the calculation of reflection-mode XAS spectra even for those sample systems where the roughness at the interfaces is similar to the layer thickness.

Owing to the calculation procedure, these simulated reflectivity spectra $R(E, \Theta)$ contain the near-range order structural information of the chosen model compounds, either by a direct input of structural parameters and an $a b$ initio calculation of the refractive index (Lützenkirchen-Hecht \& Frahm, 2006; Benzi et al., 2008) or by using spectra of suited reference compounds (Borthen \& Strehblow, 1997; Lützenkirchen-Hecht et al., 2003). Here we have used high-quality transmission-mode XAS data which were obtained from polycrystalline reference materials (metal foils, oxide powders) at beamlines RÖMO 2 and BW1 at HASYLAB (DESY, Hamburg, Germany) operating with 100-150 mA of $4.45 \mathrm{GeV}$ positrons. While home-made computer-programs were used for the calculation of the reflectivity data, the data reduction was performed using the Athena package (Ravel \& Newville, 2005) and the WinXas software (Ressler, 1998).

It should be mentioned here that the calculation scheme presented in Fig. 1 can also be used for fitting the experimental data. Thus, if the calculated specular X-ray reflectivity profile and the calculated reflection-mode EXAFS are not fitting to the experimental data adequately, new model compounds or different thicknesses of the involved materials have to be used. In addition, a multilayered structure instead of a single surface layer may also be required for the simulations in order to obtain a close fit to the experiments. Alternatively to reference compounds, $a b$ initio calculations using software codes like FEFF (e.g. Ankudinov et al., 1998) can also be used as sources for the EXAFS $[\Delta \beta(E)$ and $\Delta \delta(E)]$ and the structureless atomic contributions $\left[\beta_{0}(E)\right.$ and $\left.\delta_{0}(E)\right]$ of such reflectivity spectra. Therefore experimental reflectivity data can be directly fitted to structure models, i.e. the determination of 


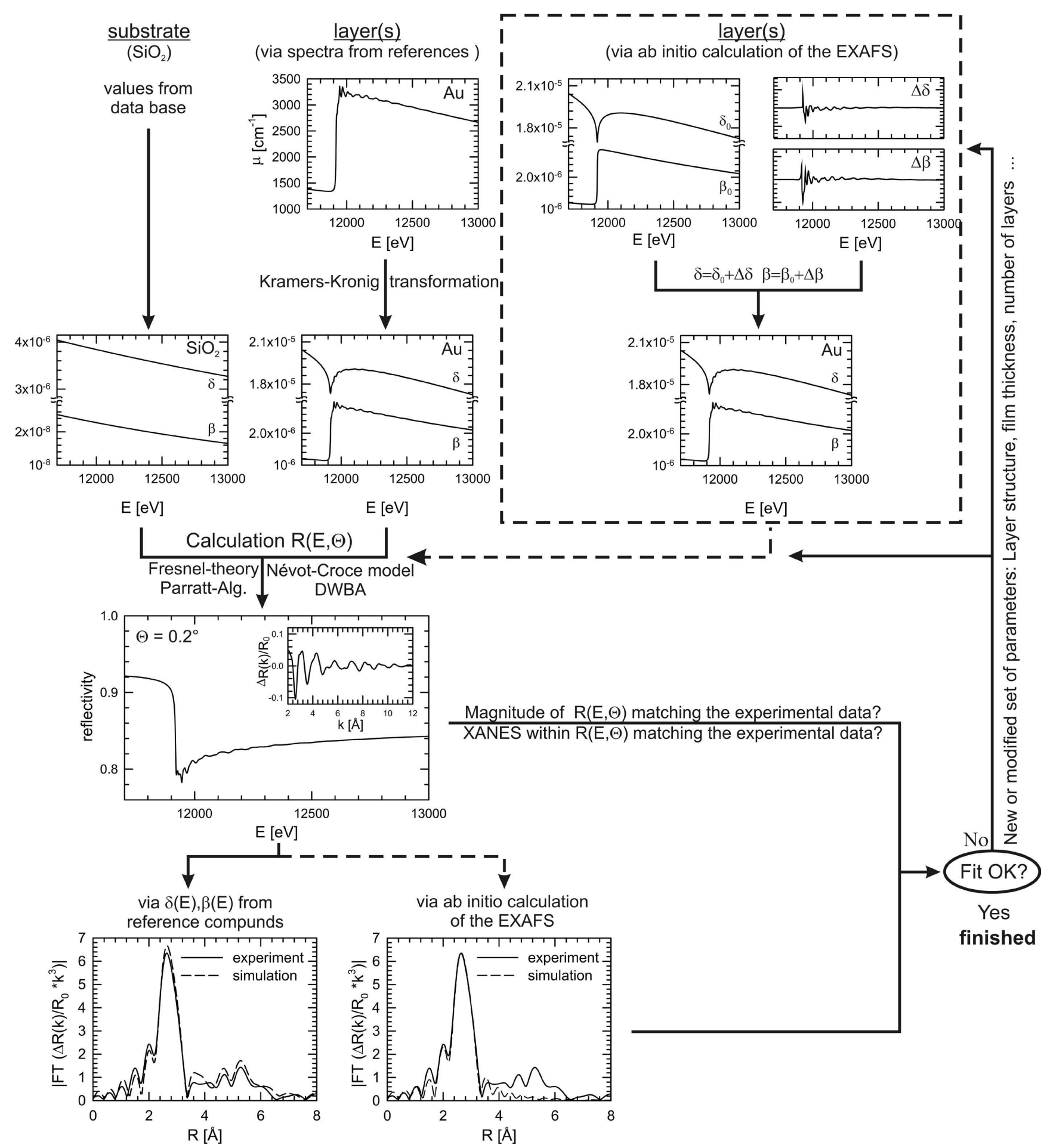

Figure 1

Basic flow chart of the calculation and data analysis scheme of reflection-mode EXAFS spectra, exemplarily shown for the Au $L_{3}$-edge EXAFS of a thin gold layer on $\mathrm{SiO}_{2}$ substrate. The optical constants $\beta(E)$ and $\delta(E)$ of the Au layer can be either approximated by those of a reference compound (e.g. polycrystalline $\mathrm{Au}$ ) or by ab initio calculations.

nearest-neighbour distances, coordination numbers and Debye-Waller factors of surface layers is enabled by adjusting the input parameters of the calculation so that the calculated and measured data show a close fit. A detailed calculation procedure for such kinds of model calculation was recently given by Benzi et al. (2008).

\section{Results and discussion}

In Fig. 2(a), calculated reflection-mode EXAFS data at the $\mathrm{Au}$ $L_{3}$-edge for a pure gold surface are presented for a grazing angle $\Theta=0.2^{\circ}$ and different r.m.s. values of the surface roughness making use of the Névot-Croce model. As 

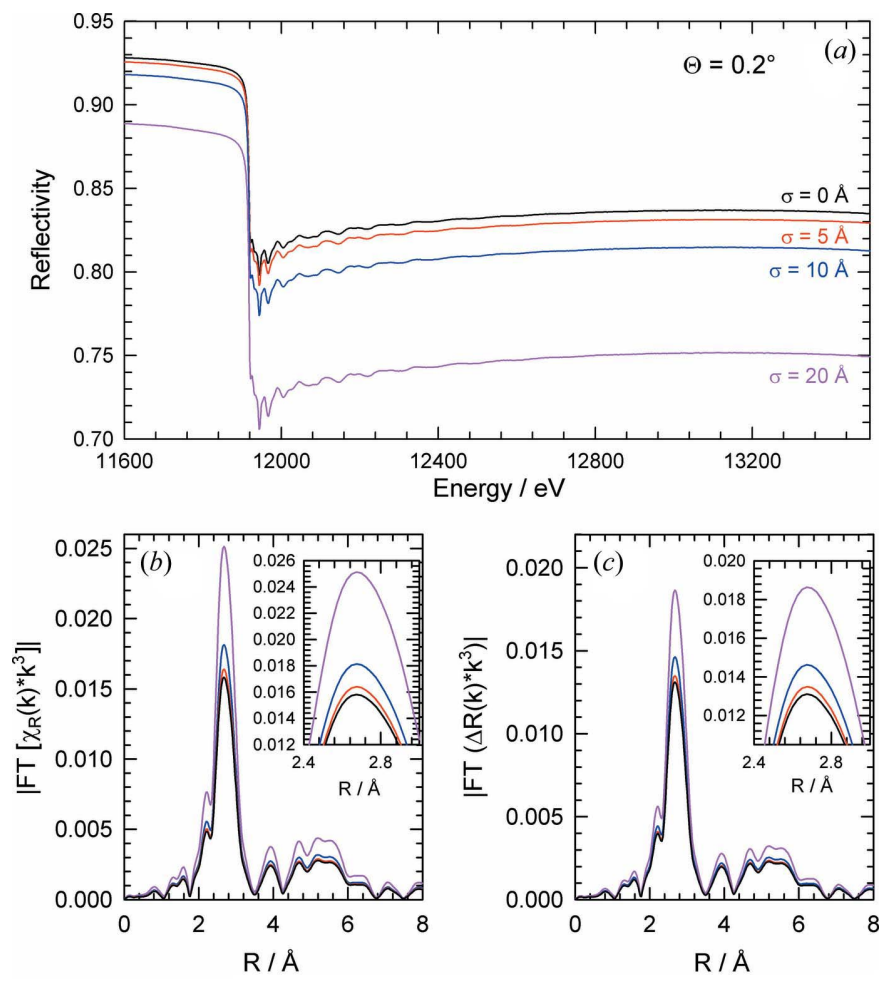

Figure 2

(a) Calculated reflection-mode EXAFS spectra for a polycrystalline gold sample at the $\mathrm{Au} L_{3}$-edge and a grazing angle $\Theta=0.2^{\circ}$ for different surface r.m.s. roughness values $\sigma$, as indicated. The magnitude of the Fourier transforms (FTs) of the $k^{3}$-weighted reflectivity fine structures extracted from these spectra are compared in $(b)\left|\mathrm{FT}\left[\chi_{\mathrm{R}}(k) k^{3}\right]\right|$ and $(c)$ $\mid \mathrm{FT}\left[\Delta R(k) k^{3}\right]$, respectively. Black line: Fresnel reflectivity $(\sigma=0 \AA)$. Red line: $\sigma=5 \AA$. Blue line: $\sigma=10 \AA$. Purple line: $\sigma=20 \AA$. The insets show the behaviour of the FT in the vicinity of the nearest-neighbour peak in more detail. The data are not corrected for phase shifts; $k$-range for the FT: $4.5 \AA^{-1}<k<12.5 \AA^{-1}$.

previously shown, the DWBA gave identical results (see Keil et al., 2005b), so we only show one data set here. As expected, the overall reflectivity decreases with increasing surface roughness $\sigma$. While only smaller changes can be detected for $\sigma=5 \AA$, a steep reduction of $R(E)$ results for $\sigma=20 \AA$, and it should be noted that the decrease in the energy region above the edge is always larger compared with that in the pre-edge region. This observation directly demonstrates the importance of surface roughness for grazing-incidence X-ray absorption spectroscopy.

In Figs. 2(b) and 2(c), the Fourier-transformed reflectivity fine-structure data are presented in two different representations as follows. In Fig. 2(b), the magnitude of the Fourier transform (FT) of the so-called reduced-reflectivity fine structure

$$
\chi_{\mathrm{R}}(k)=\left[R(k)-R_{0}(k)\right] / R_{0}(k)=\Delta R(k) / R_{0}(k),
$$

is presented, where $R(k)$ is the reflectivity of the sample, $R_{0}(k)$ is the smooth atomic background and $k$ is the photoelectron wavevector, i.e. $k=\left[2 m\left(E-E_{0}\right) / \hbar^{2}\right]^{1 / 2}$, where $E$ is the photon energy and $E_{0}$ is the energy of the absorption edge under investigation, i.e. $E_{0}=11919 \mathrm{eV}$ in the case of the $\mathrm{Au} L_{3}$-edge. It should be noted that this representation is most often used in the literature. In the second graph (Fig. 2c), the magnitude of the FT of $\Delta R(k)$ is depicted without any further normalizations. Both methods have been used in many papers in the past, but both representations in parallel were scarcely shown. Prior to the calculation of the Fourier transform, the fine structures were $k^{3}$-weighted in order to amplify fine-structure contributions at higher $k$ values. As can be seen in both figures, the increase of the surface roughness leads to increasing peak intensities in both Fourier transforms. This is an important observation, because several authors in the past have assumed that, by using the reduced reflectivity $\chi_{\mathrm{R}}(k)$, the effect of surface roughness should cancel out in the data treatment, which is obviously not the case.

Furthermore, by comparing Figs. 2(b) and 2(c), it can be seen that the increase of the peak maxima with increasing roughness is less pronounced in the case of the FT $\left[\Delta R(k) k^{3}\right]$. For example, for the first-neighbour peak at about $2.7 \AA$ radial distance, the magnitude of FT $\left[\Delta R(k) k^{3}\right]$ has a peak value of about 0.0131 for the Fresnel reflectivity without considering roughness and $\sim 0.0186$ for the $20 \AA$ roughness, which corresponds to an increase by about $142 \%$. In the case of the $\mid \mathrm{FT}$ $\left[\chi_{\mathrm{R}}(k) k^{3}\right] \mid$ representation, the increase from $\sim 0.0157$ to $\sim 0.0251$ amounts to about $160 \%$. Although the effect of roughness is slightly suppressed if pure reflectivities are considered, we can therefore conclude from these calculations that surface roughness has always to be taken into account for a proper data analysis of reflection-mode XAS experiments.

In practical surface analysis studies, it is in some cases only feasible to measure the X-ray absorption near-edge structure (see, for example, Davenport \& Sansone, 1995; Schmuki et al., 1996). For (multi-)layered samples, the data analysis in such cases may be extremely difficult because the penetration depth of the X-rays into matter varies dramatically if the photon energy is scanned in the vicinity of an absorption edge while the incidence angle is fixed. This is shown for $\mathrm{Cu}_{2} \mathrm{O}$ (cuprite) at the $\mathrm{Cu} K$-edge in Fig. 3 for several different grazing angles. As can be seen, the penetration depth $z$ amounts to only some few nanometres for incidence angles

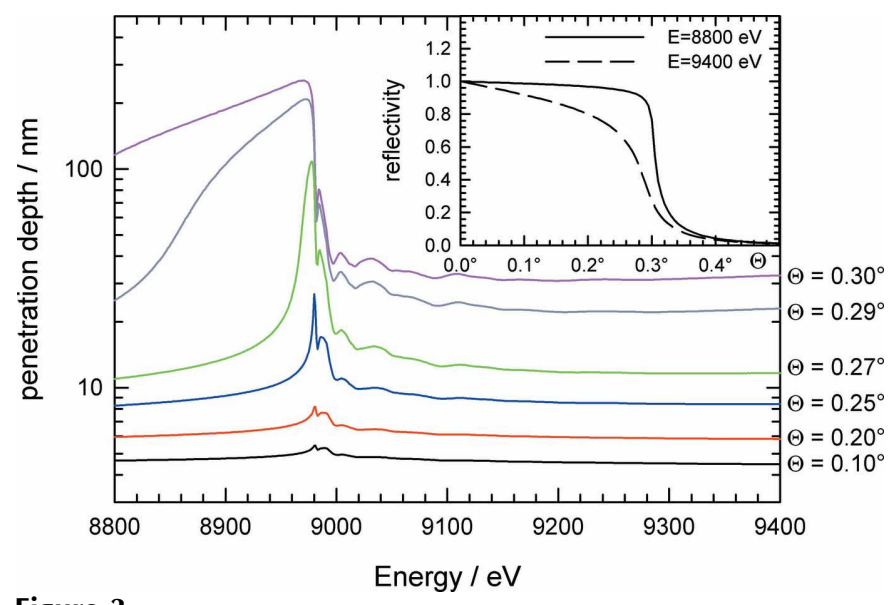

Figure 3

Penetration depth $z$ of X-rays into crystalline $\mathrm{Cu}_{2} \mathrm{O}$ in the vicinity of the $\mathrm{Cu} K$-edge for different grazing angles as indicated. The reflectivity at different fixed energies is shown in the inset as indicated. 
smaller that the critical angle of total reflection, which amounts to about $\Theta_{c}=0.29^{\circ}$. If $\Theta$ is well below $\Theta_{c}, z$ is almost constant throughout the shown energy range. However, if the critical angle is approached for e.g. $\Theta=0.25^{\circ}$ or $\Theta=0.27^{\circ}, z$ shows a distinct peaked behaviour in the close vicinity of the absorption edge, with a maximum penetration depth of the order of about $100 \mathrm{~nm}$ for $\Theta=0.27^{\circ}$, while $z$ amounts to $\sim 11 \mathrm{~nm}$ below and above the edge. It is noteworthy to mention here that $z$ is still approximately constant in the EXAFS part of the spectrum for any chosen incidence angle, and thus a depth profiling by EXAFS spectroscopy seems to be feasible as stated by other authors in the past. However, the strong variation of the penetration depth in the edge region makes XANES investigations difficult, for the following reasons. First of all the features in the near-edge spectrum themselves are changing in their relative intensities as a function of the grazing angle even in the case of a semi-infinite sample. In such a case, variations detected in near-edge spectra may be misinterpreted because they are just the consequence of a changed roughness and an accordingly modified X-ray penetration into the sample. Second, and more intriguing, in the case of a layered system the substrate or any underlying material may contribute in different amounts accordingly. One may argue that some of those implications may be overcome by performing the reflection-mode EXAFS scans in such a way that the $z$-component of the scattering wavevector $q_{z}=$ $4 \pi \sin \Theta / \lambda$ is kept constant during the scan by a small variation of the incidence angle $\Theta$ simultaneously with the photon energy. However, since the penetration depth of the X-rays is mainly determined by the energy dependence of $\delta$ and $\beta$, the dramatic changes of $z$ at the edge will still be present, even if such a complication to the scattering geometry is added. Furthermore, the changes of $q_{z}$ in a typical EXAFS scan are usually small. Assuming, for example, an incidence angle of $\Theta=0.2^{\circ}, q_{z}$ varies from $0.031 \AA^{-1}$ at $8800 \mathrm{eV}$ in the pre-edge region to $\sim 0.032 \AA^{-1}$ directly at the $\mathrm{Cu} K$-edge at $8979 \mathrm{eV}$, to $\sim 0.033 \AA^{-1}$ at $9400 \mathrm{eV}$.

We have therefore performed calculations on a model system consisting of a thin layer composed of $\mathrm{Cu}_{2} \mathrm{O}$ (crystalline cuprite) on metallic copper, i.e. the $\mathrm{X}$-ray absorbing species is present in both the overlayer and the substrate. The layer thickness was set to $3.5 \mathrm{~nm}$, and therefore the whole copper oxide film is penetrated by the X-rays even for incidence angles smaller than $\Theta_{c}$. The roughness of the outer air$\mathrm{Cu}_{2} \mathrm{O}$ surface and the inner $\mathrm{Cu}_{2} \mathrm{O}-\mathrm{Cu}$ metal interface were varied systematically. The calculations were performed in the framework of the Névot-Croce model and the results are compiled in Fig. 4. It should be mentioned at this point that calculations of the same $\mathrm{Cu}_{2} \mathrm{O}-\mathrm{Cu}$ system utilizing the DWBA lead to identical results. As can be seen, the edge jump increases continuously with increasing roughness $\sigma_{1}$ of the outer $\mathrm{Cu}_{2} \mathrm{O}$ layer if the interface roughness between the $\mathrm{Cu}_{2} \mathrm{O}$ and the $\mathrm{Cu}$ metal is set $\sigma_{2}=0$. In addition, the near-edge features, e.g. the absorption maximum at $8992 \mathrm{eV}$, are also increasing with $\sigma_{1}$, which demonstrates the difficulty of a quantitative analysis of near-edge absorption features in the case of rough surfaces. In contrast, for $\sigma_{1}=0$, the edge jump as
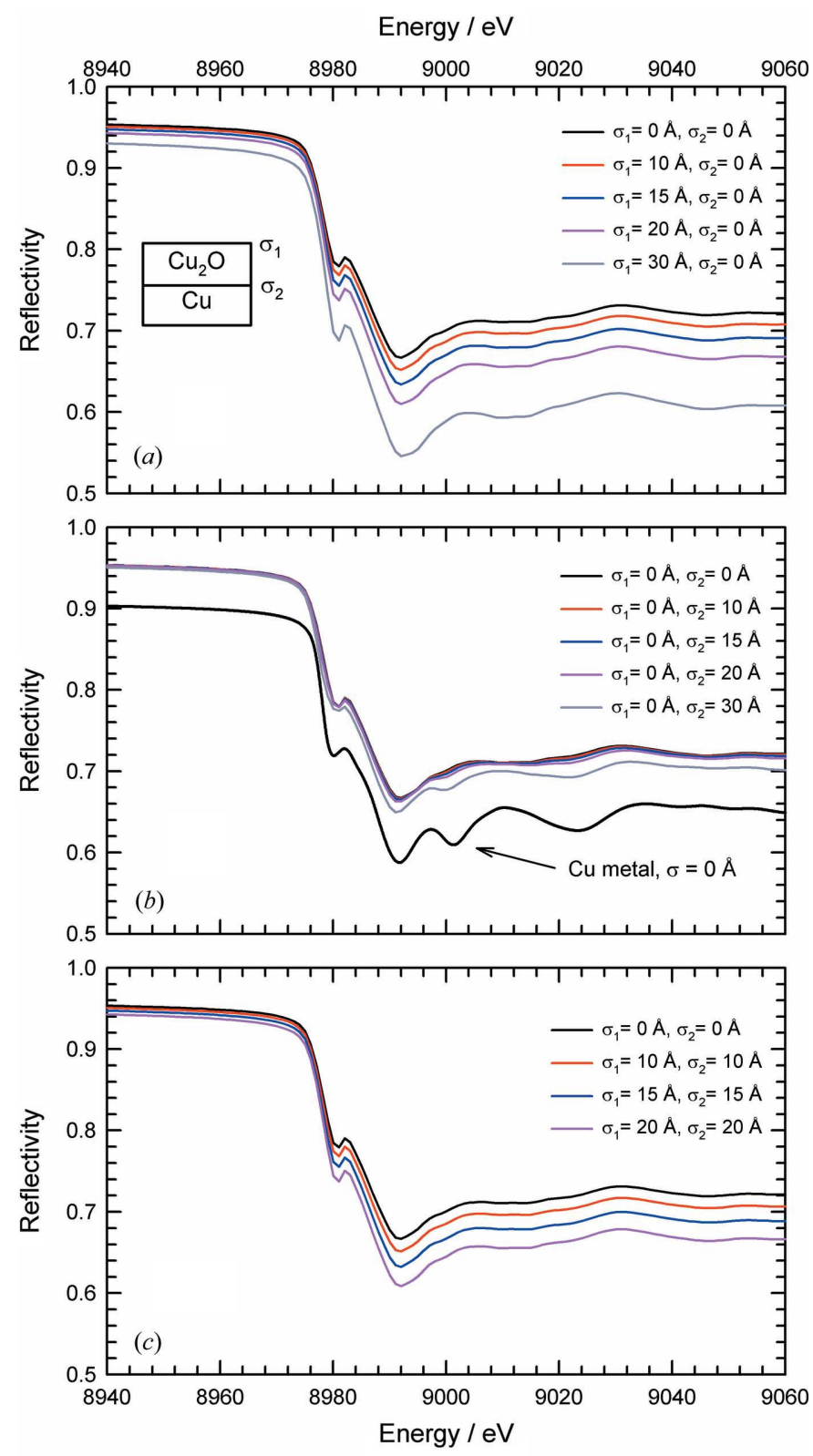

Figure 4

Calculated reflection-mode X-ray absorption near-edge spectra for a layer of $3.5 \mathrm{~nm}$ crystalline $\mathrm{Cu}_{2} \mathrm{O}$ on a copper metal substrate [as shown schematically in the inset of Fig. 3(a) $]$ and a grazing angle $\Theta=0.2^{\circ}$ and various different r.m.s. roughness values for the $\mathrm{Cu}_{2} \mathrm{O}$ /air surface $\left(\sigma_{1}\right)$ and the inner $\mathrm{Cu}_{2} \mathrm{O} / \mathrm{Cu}$ interface $\left(\sigma_{2}\right)$ as indicated. For comparison, a spectrum of a smooth $(\sigma=0 \AA)$ oxide-free $\mathrm{Cu}$ metal sample is shown in (b); this spectrum is shifted downwards by 0.05 for a better visualization.

well as the reflectivity remain almost unaffected if the inner interface roughness $\sigma_{2}$ is increased. Only for $\sigma_{2}=30 \AA$ does the double-peaked XANES features typical for metallic copper appear at $\sim 8992 \mathrm{eV}$ and $9001 \mathrm{eV}$. For comparison, we have included a spectrum calculated for a pure metallic $\mathrm{Cu}$ sample neglecting roughness. As can be seen, the mentioned structures are characteristic of metallic copper as already stated, and therefore we can conclude that roughening of the inner $\mathrm{Cu}_{2} \mathrm{O} / \mathrm{Cu}$ interface obviously leads to more pronounced contributions of the underlying metal to the XANES signals, and a quantitative fit of the spectrum would have led to an 
overestimation of the metallic content in comparison with the $\mathrm{Cu}$ oxide surface layer. On the other hand, owing to the more developed oxidic absorption features which result from the roughening of the outer surface, the $\mathrm{Cu}_{2} \mathrm{O}$ contribution or the thickness of the oxide layer would have been overestimated if the influence of surface and interface roughness were neglected. In Fig. 4(c), both interfaces are afflicted with a nonvanishing roughness. No clear trend can be found here, but, as those calculations have shown, the interplay between the roughness parameters of both contributing interfaces seems to be essential for the quantitative analysis of reflection-mode $\mathrm{X}$-ray absorption near-edge spectra measured at grazing incidence.

In Fig. 5, results of simulations covering the full EXAFS range (i.e. up to $\sim 700 \mathrm{eV}$ above the $\mathrm{Cu} K$-edge) of the same sample system are presented for an incidence angle $\Theta=0.2^{\circ}$. Clear signatures of cuprite and copper metal are found in the shown Fourier transforms, which can be expected from the penetration depth of the X-rays of about $6 \mathrm{~nm}$ (see Fig. 3). As can be seen in Fig. 5(a), an increase in the surface roughness of the outer air-cuprite surface leads to an increase of peak intensity of those peaks which belong to oxide coordinations, most prominently the nearest-neighbour $\mathrm{Cu}-\mathrm{O}$ peak at about $1.3 \AA$ and the first $\mathrm{Cu}-\mathrm{Cu}$ coordination in the oxide at $2.8 \AA$. All the peaks are shifted towards smaller distances because of the phase shifts of the scattered photoelectrons, i.e. the true crystallographic distances are $1.826 \AA$ and $2.982 \AA$ for the two oxide shells and $2.556 \AA$ for the first coordination of $\mathrm{Cu}$ metal. This peak of the underlying metal at about $2.2 \AA$ radial distance and additional $\mathrm{Cu}$ metal peaks between $\sim 4 \AA$ and $6 \AA$ do not change systematically in intensity when the surface roughness of the outer oxide surface is increased. In contrast, if the roughness of the outer surface is kept identical to zero and the roughness of the inner oxide/metal interface is varied, mostly those coordinations belonging to the metal are affected (Fig. 5b). Again, an increasing interface roughness leads to increasing peak intensities. However, the peaks of the oxide, especially the $\mathrm{Cu}-\mathrm{Cu}$ coordination of the oxide at $\sim 2.8 \AA$ radial distance, are also slightly affected; however, their intensities are decreasing with increasing interface roughness. In Figs. 5(c) and 5(d), both the roughness at the inner and the outer interfaces were afflicted with a non-zero roughness. As can be seen in Fig. 5(c), identical values of both roughness parameters seem to have only a small influence on the calculated reflection-mode EXAFS spectra, as the intensities of all peaks are only increased by about $3-5 \%$ for $10 \AA$ and by about $7-15 \%$ for $15 \AA$ surface/interface roughness. The last simulation clearly shows that one has to be very careful when reflection-mode XAS data are only available for a single grazing angle. Here the roughness parameter of the outer surface is set constant to $\sigma_{1}=10 \AA$, and the influence of $\sigma_{2}$ on the resulting EXAFS spectra is demonstrated. As can be seen here, the increase of $\sigma_{2}$ leads to a steep decrease in intensity of all the oxide coordinations, while that of the $\mathrm{Cu}-\mathrm{Cu}$ of the metal is strongly enhanced. However, the damping in the oxide intensity is not as developed as the increase of the metal peaks. Although the effects shown in Figs. 4 and 5 are quite
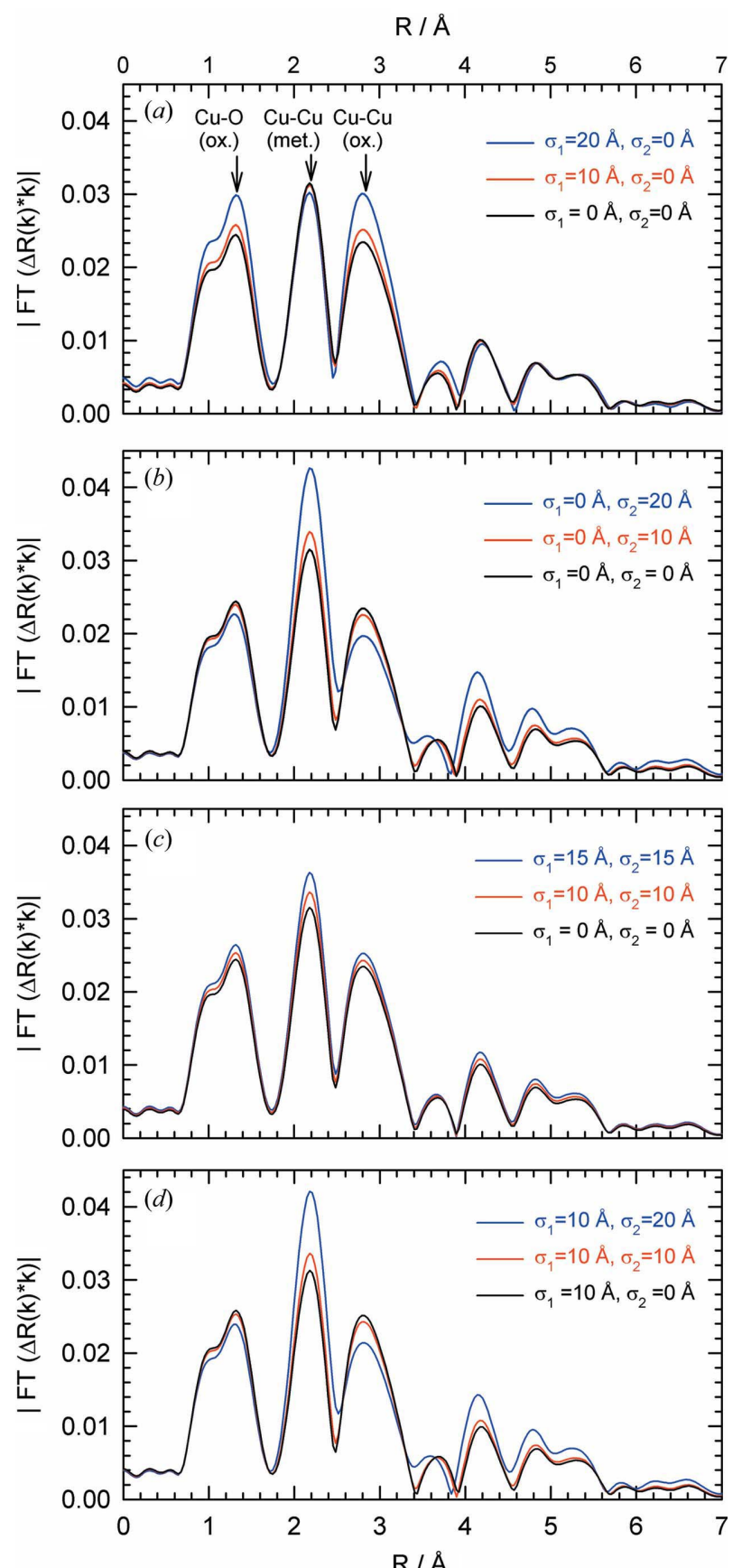

Figure 5

$\mathrm{R} / \AA$

Magnitude of the Fourier transforms (not phase-shift corrected) of the $k$ weighted reflectivity fine structures for calculated reflection-mode EXAFS data $\left(\Theta=0.2^{\circ}\right)$ from a $3.5 \mathrm{~nm}$ thin $\mathrm{Cu}_{2} \mathrm{O}$ layer on a copper metal substrate for different surface $\left(\sigma_{1}\right)$ and interface $\left(\sigma_{2}\right)$ r.m.s. roughness values, as indicated. The calculations were performed in the framework of the DWBA assuming a correlation length of $\xi=50 \mathrm{~nm}$ and a Hurst parameter $h=1$ for both interfaces. Calculations within the Névot-Croce model lead to the same FTs. The peaks at $R_{1} \simeq 1.3 \AA$ and $R_{3} \simeq 2.8 \AA$ are related to the first $\mathrm{Cu}-\mathrm{O}$ and $\mathrm{Cu}-\mathrm{Cu}$ coordination shells of the copper oxide; the maximum at $R_{2} \simeq 2.2 \AA$ belongs to the first $\mathrm{Cu}-$ $\mathrm{Cu}$ coordination of metallic copper. ( $k$-range for the FTs: $1.75 \AA^{-1}<k<$ $11.75 \AA^{-1}$.)

intriguing, it is difficult to provide an illustrative model for these observations because, statistically, most of the scattering processes of the photoelectron waves which are responsible for the EXAFS will occur well away from the surface. 
However, as the roughness determines or at least strongly influences the decay of the electric field strength with depth in the sample, it is on the other hand clear that regions in different depths of the sample contribute to the reflectivity signal with varying intensity, and the total reflectivity signal is a weighted sum over all these different contributions (Parratt, 1954; Born \& Wolf, 1975; Król et al., 1988). If a thin film on a substrate is assumed, the variations of the surface and interface roughness thereby change the distribution of the X-ray absorbing species within the penetration depth of the X-rays (de Boer, 1996), and in the detected reflectivity EXAFS signal the respective contributions are affected accordingly.

More data are compiled in Figs. $6(a)-6(c)$, where the peak intensities of the mentioned oxide $\left(R_{1}, R_{3}\right)$ and metal $\left(R_{2}\right)$
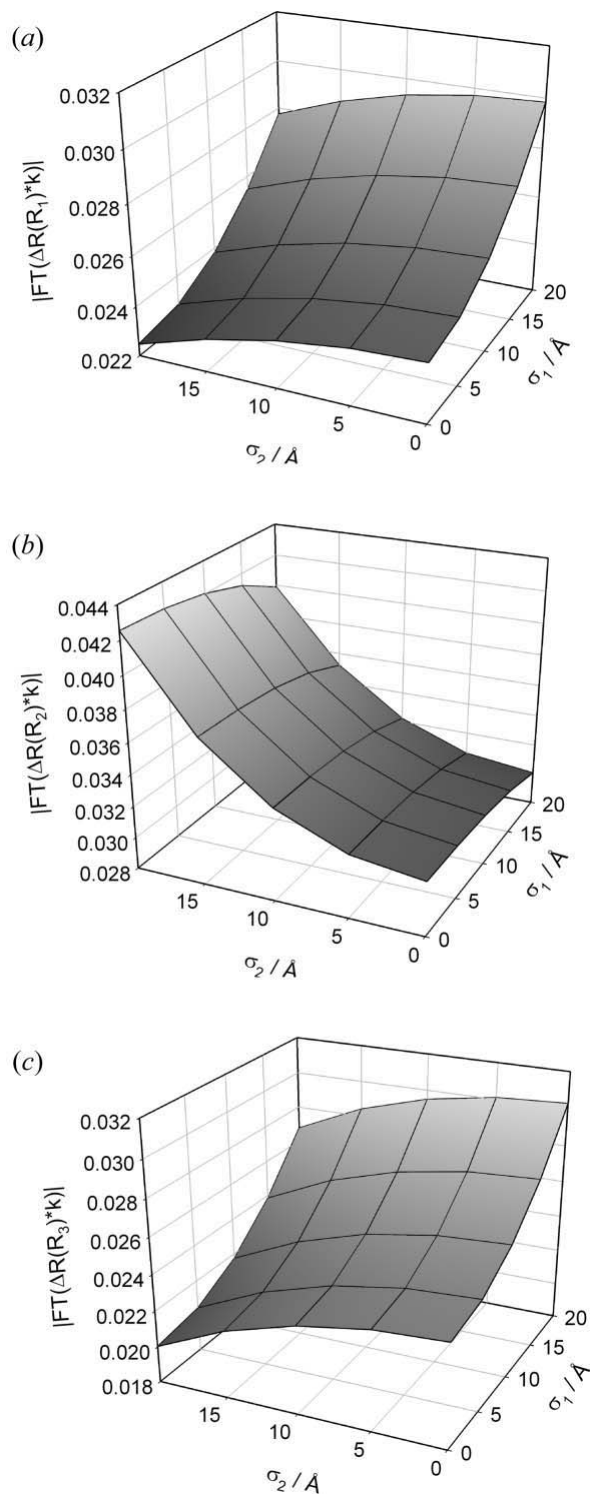

Figure 6

Systematic variations of the peaks belonging to the first $\mathrm{Cu}-\mathrm{O}$ shell of the oxide at $R_{1}(a)$, the first $\mathrm{Cu}-\mathrm{Cu}$ shell of metallic copper at $R_{2}(b)$, and the $\mathrm{Cu}-\mathrm{Cu}$ shell of the oxide at $R_{3}(c)$ as a function of the surface and interface r.m.s. roughness parameters $\sigma_{1}$ and $\sigma_{2}$ according to a simulation assuming a $3.5 \mathrm{~nm}$-thick $\mathrm{Cu}_{2} \mathrm{O}$ film on $\mathrm{Cu}$ and an incidence angle of $\Theta=0.2^{\circ}$. peaks are plotted as a function of the roughness parameters $\sigma_{1}$ and $\sigma_{2}$. Peaks $R_{1}$ and $R_{3}$ obviously show a similar, but not identical, behaviour whereas peak $R_{2}$ reveals a directly opposed trend.

We can conclude here that the various peaks in the Fourier transforms belonging to species within the layer or to those located in the substrate have a different response to the different roughness parameters in the case of rough surfaces and interfaces, and therefore any quantitative reflection-mode EXAFS data analysis may be directly affected. Moreover, if surface and interface roughness are neglected, data misinterpretations are possible as will be demonstrated by considering our $\mathrm{Cu}_{2} \mathrm{O} / \mathrm{Cu}$ model system $\left(3.5 \mathrm{~nm} \mathrm{Cu}_{2} \mathrm{O}\right.$ on $\left.\mathrm{Cu}\right)$ again. Assuming that this thin copper oxide layer is grown homogeneously on a copper metal, it can be assumed that the roughness of both involved interfaces is identical, i.e. $\sigma_{1}=\sigma_{2}$. We have chosen a roughness $\sigma_{1}=\sigma_{2}=15 \AA$ which is a reasonable value for a real surface. Let us now consider the three major peaks $R_{1}, R_{2}$ and $R_{3}$ separately, i.e. the FT was fitted to a theoretical model without accounting for roughness and just matching the value of the peak position and intensity by varying the thickness of the $\mathrm{Cu}_{2} \mathrm{O}$ layer in the Fresnel theory using ideally smooth surfaces. As can be seen in Fig. 7, a self-consistent modelling of the 'experimental data' is impossible using the thickness of the oxide as the only fit parameter. While an oxide thickness of only $3.5 \mathrm{~nm}$ was used for the rough model sample, the fits disregarding roughness give $d=4.3 \mathrm{~nm}$ and $d=3.9 \mathrm{~nm}$ if the first $\mathrm{Cu}-\mathrm{O}$ at $\sim 1.3 \AA$ radial distance and the first $\mathrm{Cu}-\mathrm{Cu}$ peak of the oxide at $\sim 2.8 \AA$ are optimally fitted. For those two fits, the leading peak of the underlying metal was not reproduced adequately; the simulations gave much too small metal peak amplitudes

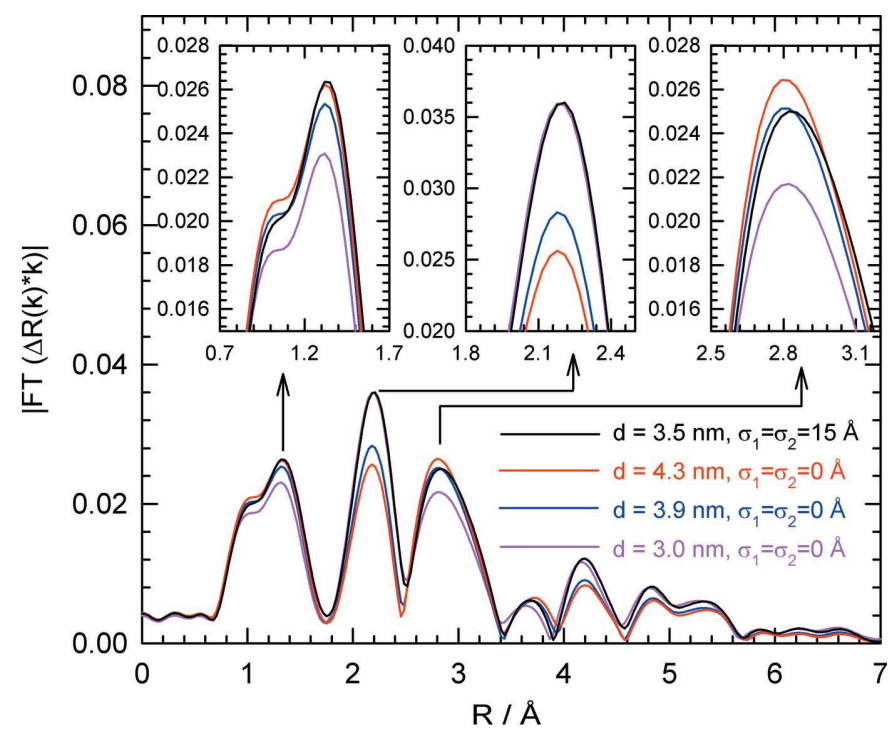

Figure 7

Magnitude of the Fourier transforms of the $k$-weighted reflectivity fine structures calculated for a $\mathrm{Cu}_{2} \mathrm{O}$ film of $3.5 \mathrm{~nm}$ thickness on a $\mathrm{Cu}$ substrate each with $15 \AA$ surface roughness compared with several model systems with different thickness of the $\mathrm{Cu}_{2} \mathrm{O}$ layer neglecting any surface and interface roughness, i.e. $\sigma_{1}=\sigma_{2}=0 \AA$. (Incidence angle $\Theta=0.2^{\circ}$; the data are not corrected for phase shifts. $k$-range for the FTs: $1.75 \AA^{-1}<k<$ $11.75 \AA^{-1}$.) 
in this situation. Even if, for example, the FT is optimally described in the region of the first peak $R_{1}$ by the calculation, then the second oxide peak $R_{3}$ is overestimated by the calculation and vice versa. In contrast, if the $\mathrm{Cu}-\mathrm{Cu}$ peak of the metal $\left(R_{2}\right.$ at $\left.\sim 2.2 \AA\right)$ is well described by a simulation without using any roughness, then an oxide layer thickness of only $3.0 \mathrm{~nm}$ results. However, the peaks of the oxide layer are in this case significantly underestimated by about $12 \%\left(R_{1}\right)$ and $18 \%\left(R_{3}\right)$. In contrast, if $R_{1}$ or $R_{3}$ are reproduced by the fit to a good approximation, then peak $R_{2}$ is underestimated by about $21 \%$ up to more than $28 \%$. In contrast to a previous publication where it was stated that any present surface roughness decreases the contributions of surface layers in the Fourier transform (Borthen \& Strehblow, 1997), the present investigation has clearly shown that the surface roughness does not have such a simple impact on the reflection-mode EXAFS data, and that the neglect of surface roughness has therefore no easily predictable influence on the obtained results. Moreover, it is also clear that all the different peaks belonging to the layer and the substrate species may not be reproduced by a simulation employing only one single roughness parameter.

In order to demonstrate practical consequences of the observed correlations and dependencies between reflectionmode EXAFS data and the involved layers and materials, we consider experimental data obtained from an oxidized copper specimen in the following. The sample consists of a sputter deposited $\mathrm{Cu}$-metal layer of $\sim 90 \mathrm{~nm}$ thickness on a float glass substrate (Pilkington, Germany), and it was exposed to laboratory air for about nine months prior to the X-ray investigations at the BW1 beamline at HASYLAB (DESY, Hamburg, Germany). Under these environmental conditions, copper is known to form thin passivating oxide films on its

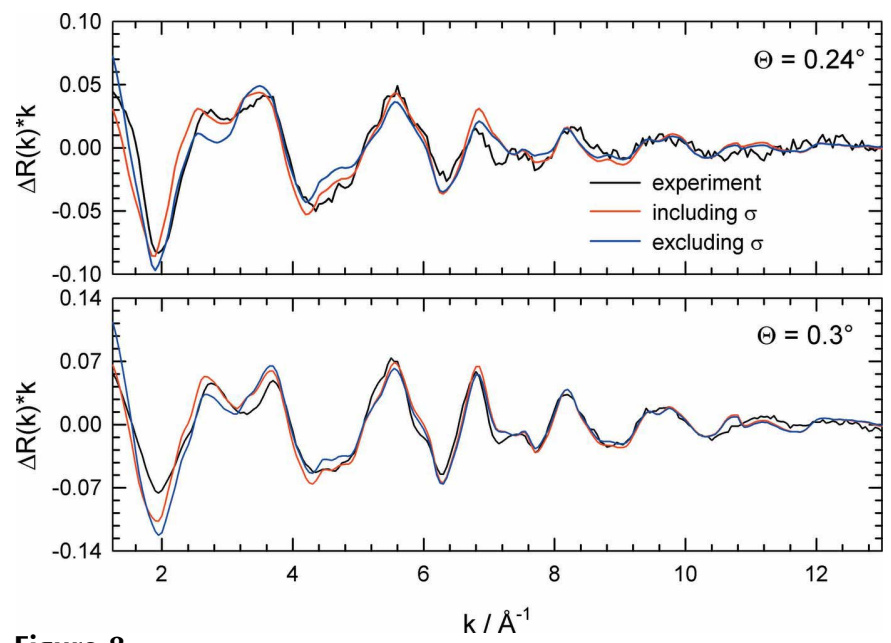

Figure 8

Comparison of the measured reflection-mode $\mathrm{Cu} K$-edge EXAFS of an oxidized $\mathrm{Cu}$ metal thin film (black line) with calculated data assuming a double-layered oxide structure with $d_{1}(\mathrm{CuO})=2.0 \mathrm{~nm}, d_{2}\left(\mathrm{Cu}_{2} \mathrm{O}\right)=$ $3.5 \mathrm{~nm}$ and $d_{3}(\mathrm{Cu}$ metal $)=88 \mathrm{~nm}$ on a glass substrate. While the first simulation (red line) includes the roughness effects for the different surfaces and interfaces (i.e. $\sigma_{1}=\sigma_{2}=\sigma_{3}=13 \AA$ for all the interfaces where the oxides are contributing, and $\sigma_{4}=4 \AA$ for the interface between the smooth glass substrate and the $\mathrm{Cu}$ film), any surface roughness is neglected in the second simulation (blue line). surfaces, which prevent the underlying metal from further oxidation or corrosive attack (e.g. Barr, 1994; Lenglet et al., 1995; Millet et al., 1995; Apen et al., 1998; Yang et al., 1998). This property is extremely important with regard to the use of $\mathrm{Cu}$ in microelectronic circuits etc. (Frankenthal, 1990; Koetter et al., 2000). Several different reactions were considered to be involved in the oxide film formation, i.e.

$$
\begin{aligned}
2 \mathrm{Cu}+\mathrm{H}_{2} \mathrm{O} & \rightarrow \mathrm{Cu}_{2} \mathrm{O}+\mathrm{H}_{2}, \\
\mathrm{Cu}+\mathrm{H}_{2} \mathrm{O} & \rightarrow \mathrm{CuO}+\mathrm{H}_{2}, \\
\mathrm{Cu}+2 \mathrm{H}_{2} \mathrm{O} & \rightarrow \mathrm{Cu}(\mathrm{OH})_{2}+\mathrm{H}_{2},
\end{aligned}
$$

although the first process seems to dominate according to Barr (1994) and Apen et al. (1998). In Figs. 8 and 9 we present results of reflection-mode EXAFS spectra measured at the $\mathrm{Cu}$ $K$-edge for different grazing angles below, at and above the critical angle of total reflection, which amounts to $\Theta_{c} \simeq 0.29^{\circ}$, and in Fig. 10 we present a conventional specular X-ray reflectivity profile for a photon energy of $8048 \mathrm{eV}(\lambda=$ $1.54 \AA$ ); here the incidence angle scale was converted to a scattering wavevector $q_{z}$ scale according to $q_{z}=4 \pi \sin \Theta / \lambda$.
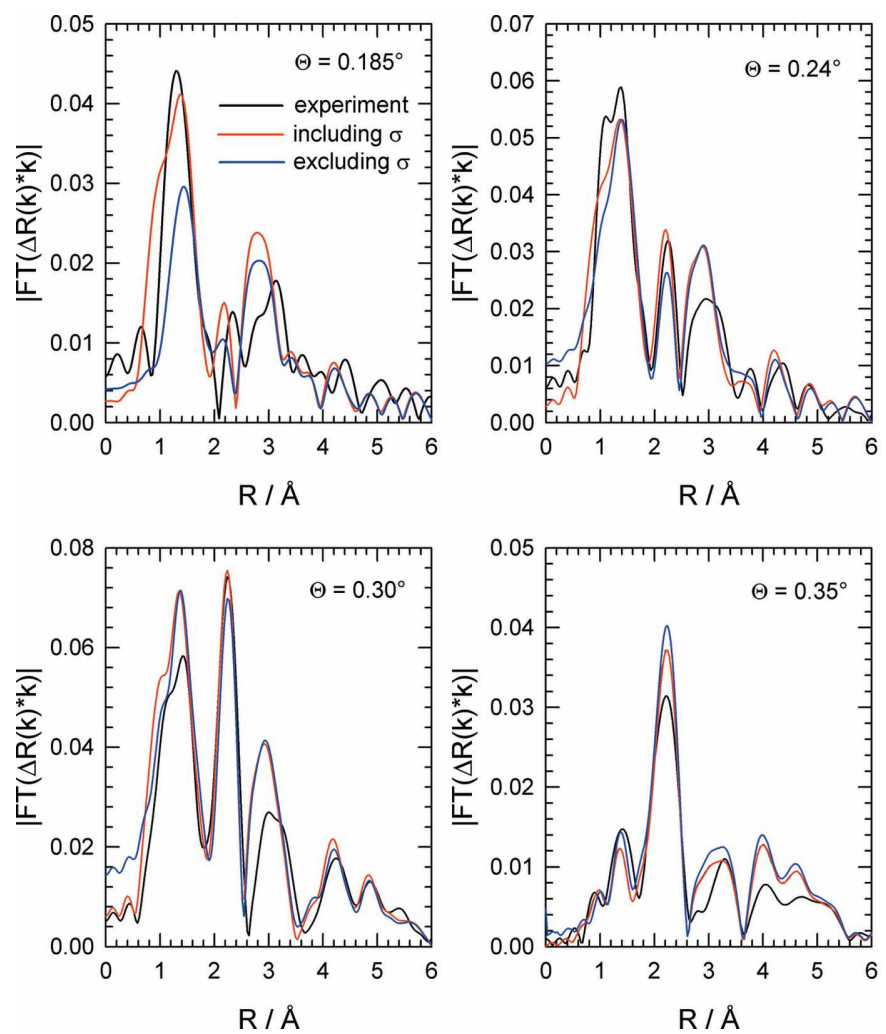

Figure 9

Comparison of the Fourier transforms of measured reflection-mode $\mathrm{Cu}$ $K$-edge EXAFS of an oxidized $\mathrm{Cu}$ metal thin film (black line) with those of calculated data assuming a double-layered oxide structure with $d_{1}(\mathrm{CuO})=2.0 \mathrm{~nm}, d_{2}\left(\mathrm{Cu}_{2} \mathrm{O}\right)=3.5 \mathrm{~nm}$ and $d_{3}(\mathrm{Cu}$ metal $)=88 \mathrm{~nm}$ on a glass substrate. While the first simulation (red line) includes the roughness effects for the different surfaces and interfaces (i.e. $\sigma_{1}=\sigma_{2}=\sigma_{3}$ $=13 \AA$ for all the interfaces where the oxides are contributing, and $\sigma_{4}=$ $4 \AA$ for the interface between the smooth glass substrate and the $\mathrm{Cu}$ film), any surface roughness is neglected in the second simulation (blue line). ( $k$-range for the FTs: $1.75 \AA^{-1}<k<11.75 \AA^{-1}$ for $\Theta=0.185^{\circ}$; for all other experiments at larger angles, $1.75 \AA^{-1}<k<12.75 \AA^{-1}$.) 


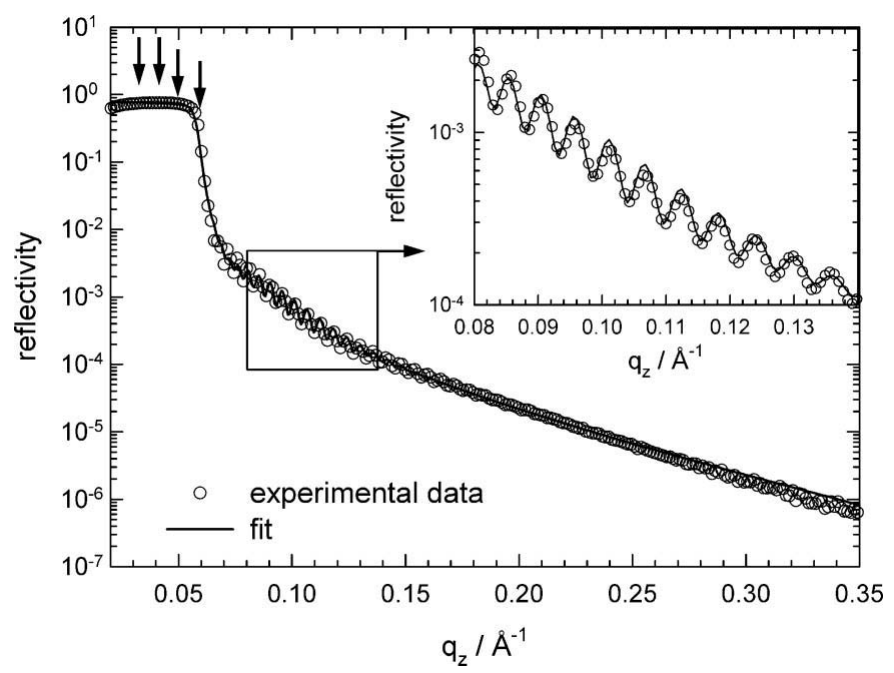

Figure 10

Specular X-ray reflectivity (symbols) and fit (line) for $8048 \mathrm{eV}$ photons $(\lambda=1.54 \AA$ ) of the oxidized $\mathrm{Cu}$ metal thin film with the corresponding EXAFS data shown in Figs. 8 and 9. The data refinement was performed by assuming a $\mathrm{CuO} / \mathrm{Cu}_{2} \mathrm{O}$ double-layered oxide structure on top of the thin copper film. The fit results are: $d_{1}(\mathrm{CuO})=2.2 \mathrm{~nm}, d_{2}\left(\mathrm{Cu}_{2} \mathrm{O}\right)=3.2 \mathrm{~nm}$ and $d_{3}(\mathrm{Cu}$ metal $)=90.9 \mathrm{~nm}, \rho_{1}(\mathrm{CuO})=6.1 \mathrm{~g} \mathrm{~cm}^{-3}, \rho_{2}\left(\mathrm{Cu}_{2} \mathrm{O}\right)=$ $5.7 \mathrm{~g} \mathrm{~cm}^{-3}$ and $\rho_{3}(\mathrm{Cu}$ metal $)=8.4 \mathrm{~g} \mathrm{~cm}^{-3}, \sigma_{1}=\sigma_{2}=\sigma_{3}=12 \AA$ and $\sigma_{4}=$ $4 \AA$, whereas the same value for the roughness was assumed for the data refinement for all the interfaces where the oxides are contributing. The inset displays a magnification of the region well above the critical angle of total reflection to resolve the thickness fringes more clearly. The vertical arrows indicate the maximal $q_{z}$ values of the reflection-mode EXAFS data shown in Fig. $9\left(\Theta=0.185^{\circ}: 0.029 \AA^{-1}<q_{z}<0.032 \AA^{-1} ; \Theta=0.24^{\circ}\right.$ : $0.038 \AA^{-1}<q_{z}<0.041 \AA^{-1} ; \Theta=0.3^{\circ}: 0.048 \AA^{-1}<q_{z}<0.051 \AA^{-1}$; and $\Theta=$ $0.35^{\circ}: 0.056 \AA^{-1}<q_{z}<0.06 \AA^{-1}$.)

Assuming a duplex structure of the oxide with an outer $\mathrm{CuO}$ and an inner $\mathrm{Cu}_{2} \mathrm{O}$ layer, a quantitative fit of the experimental data was obtained, yielding $d_{1}(\mathrm{CuO})=2.2 \mathrm{~nm}, d_{2}\left(\mathrm{Cu}_{2} \mathrm{O}\right)=$ $3.2 \mathrm{~nm}$ and $d_{3}(\mathrm{Cu}$ metal $)=90.9 \mathrm{~nm}, \rho_{1}(\mathrm{CuO})=6.1 \mathrm{~g} \mathrm{~cm}^{-3}$, $\rho_{2}\left(\mathrm{Cu}_{2} \mathrm{O}\right)=5.7 \mathrm{~g} \mathrm{~cm}^{-3}$ and $\rho_{3}(\mathrm{Cu}$ metal $)=8.4 \mathrm{~g} \mathrm{~cm}^{-3}, \sigma_{1}=$ $\sigma_{2}=\sigma_{3}=12 \AA$ and $\sigma_{4}=4 \AA$. The high quality of the fit can be seen more clearly in the inset of Fig. 10, where the $q_{z}$ range between $0.08 \AA^{-1}$ and $0.14 \AA^{-1}$ is shown in a magnified view. One may argue that using only one single roughness parameter for all these different surfaces and interfaces may not be adequate in the present situation. However, previous X-ray reflectivity experiments have shown that thin oxide layers of some few nanometres seem to follow the contour of the underlying metal (You et al., 1992), and thus it seems reasonable to assume that the duplex film has approximately the same surface and interface roughness as the underlying metal, and more specifically also the interfaces within the oxide scale. Furthermore, such a simplification reduces the number of free fit variables considerably, although a variation is in principle possible. The fit quality in addition also supports that this assumption is justified.

We have used these values as a starting point for the fit of the reflection-mode EXAFS data shown in Figs. 8 and 9. The refinement shows that the values for the roughness parameters do not need to be changed, but it finally yields slightly changed thickness values for the contributing layers, i.e. a value of $d_{1}=$ $2.0 \mathrm{~nm}$ for the outer $\mathrm{CuO}$ layer, $d_{2}=3.5 \mathrm{~nm}$ for the inner $\mathrm{Cu}_{2} \mathrm{O}$ layer, and $d_{3}=87.0 \mathrm{~nm}$ for the $\mathrm{Cu}$ metal substrate. For comparison, we show a second simulation in which all surface roughness is neglected, i.e. $\sigma_{1}=\ldots=\sigma_{4}=0$.

First of all, it should be noted at this point that all simulations using only pure $\mathrm{Cu}_{2} \mathrm{O}$-type oxide layer cannot match the experimental data satisfactorily. While the scattering contrast between $\mathrm{CuO}$ and $\mathrm{Cu}_{2} \mathrm{O}$ is relatively weak in the specular reflectivity profiles because of their similar densities, both compounds reveal significantly different features in their $\mathrm{X}$-ray absorption spectra, and they can thus be separated quite easily. Therefore especially the fitting of our experimental reflection-mode EXAFS data gave clear evidence for the presence of a duplex copper oxide layer with a $\mathrm{CuO}$ layer in contact with the oxidizing atmosphere and an inner $\mathrm{Cu}_{2} \mathrm{O}$ layer in contact with the metal; such a layering of the oxide was previously observed for the oxidation of copper in alkaline media (Strehblow \& Titze, 1980; Lohrengel et al., 1987; Melendres et al., 1998) and more recently also in the case of the native oxide formed on $\mathrm{Cu}$ in air (Iijima et al., 2006). According to Iijima et al. (2006) the formation of the native oxide layer on top of copper surfaces does not necessarily lead to an amorphous oxide structure. In fact, they have shown that at least the outermost $\mathrm{CuO}$ layer is of a polycrystalline nature which motivates the use of polycrystalline reference compounds for the calculation of the reflection-mode EXAFS spectra in this study.

As can be seen in Fig. 8 and even more clearly in Fig. 9, the neglect of surface and interface roughness leads to larger overall differences with the experimental data. Especially for the smallest incidence angle $\Theta=0.185^{\circ}$, the amplitude of the $\mathrm{Cu}-\mathrm{O}$ nearest-neighbour peak at $1.3 \AA$ in the FT cannot at all be reproduced by the simulation, i.e. the amplitude is almost $50 \%$ too small in comparison with the experimental data. This would suggest a significantly larger film thickness of the oxide layers if only this incidence angle would be considered. However, such an enlarged thickness would at the same time result in significantly smaller metal substrate peak intensities, as with increasing top oxide layer thickness all peaks corresponding to the metal substrate would be reduced in magnitude substantially, even for grazing angles larger than the critical angle of total reflection. The importance of including the surface and interface roughness in the calculation is also reflected within the reflectivity fine structure presented in Fig. 8, where the reflectivity fine structure $\Delta R(k) k$ is shown exemplarily for two different grazing angles. Especially in the range $2 \AA^{-1}<k<5 \AA^{-1}$, the reflectivity fine-structure oscillations are better reproduced by the model calculations which included roughness, i.e. the chosen layer structure and their morphological parameters appear to be suited to describe the experimental situation.

Obviously, in most cases one can find a suitable model that fits to the experimental data well for one selected grazing angle within the framework of the Fresnel theory, simply by adapting the thickness of the contributing metal and/or oxide layers. As shown in Fig. 11 for comparison, the measured data can be fitted reasonably well by using only the Fresnel theory for film thicknesses of $d_{1}(\mathrm{CuO})=4.5 \mathrm{~nm}$ and $d_{2}\left(\mathrm{Cu}_{2} \mathrm{O}\right)=4 \mathrm{~nm}$ 


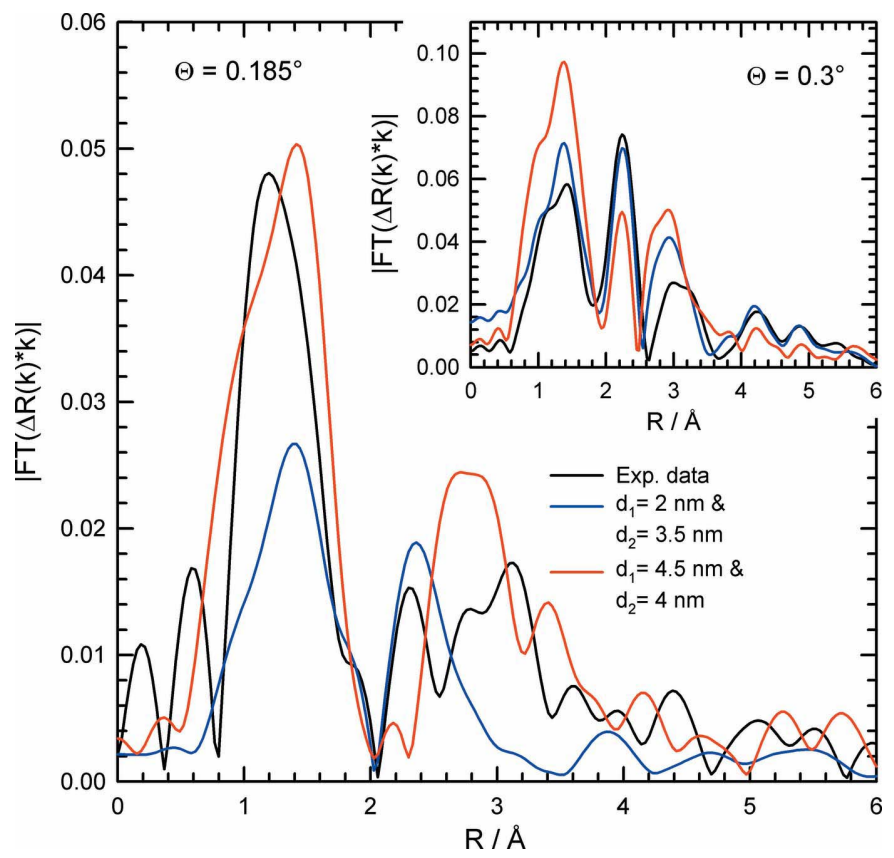

Figure 11

Comparison of the measured reflection-mode $\mathrm{Cu} K$-edge EXAFS at a grazing angle of $\Theta=0.185^{\circ}$ of an oxidized $\mathrm{Cu}$ metal thin film with calculated data assuming a double-layered oxide structure with different film thicknesses for the $\mathrm{CuO}$ layer $\left(d_{1}\right)$ and the $\mathrm{Cu}_{2} \mathrm{O}$ layer $\left(d_{2}\right)$ on top of the copper layer. All the calculations were made within the framework of the Fresnel theory neglecting roughness effects for the different surfaces and interfaces. In the inset, the calculations are compared with the measured data at a grazing angle of $\Theta=0.3^{\circ}$ ( $k$-range for the FTs: $1.75 \AA^{-1}<k<11.75 \AA^{-1}$ for $\Theta=0.185^{\circ}$, and $1.75 \AA^{-1}<k<12.75 \AA^{-1}$ for $\Theta=0.30^{\circ}$, respectively.)

at a grazing angle of $\Theta=0.185^{\circ}$. However, this data set does not at all fit to the experimental data measured for higher grazing angles, like, for example, for $\Theta=0.3^{\circ}$ which is shown for comparison in the inset of Fig. 11. In the latter case, the amplitude of the $\mathrm{Cu}-\mathrm{O}$ nearest-neighbour peak at $1.3 \AA$ as well as the first $\mathrm{Cu}-\mathrm{Cu}$ coordination of the oxides at $\sim 2.8 \AA$ radial distance cannot at all be reproduced by the simulation which gives much higher FT amplitudes for these coordinations. Additionally, a native oxide thickness of around $8.5 \mathrm{~nm}$ seems to be too large compared with values reported in the literature (see, for example, Iijima et al., 2006). In contrast, thicknesses of $d_{1}(\mathrm{CuO})=2 \mathrm{~nm}, d_{2}\left(\mathrm{Cu}_{2} \mathrm{O}\right)=3.5 \mathrm{~nm}$ give a reasonable fit for $\Theta=0.3^{\circ}$, reproducing both the metal as well as the oxide (first $\mathrm{Cu}-\mathrm{O}$ shell) peak positions and amplitudes sufficiently. Again, however, such a model is not suited for a satisfactory fit of the experimental data at the smaller grazing angle $\Theta=0.185^{\circ}$, where the oxide peaks at $\sim 1.3 \AA$ and $2.8 \AA$ are much too small in amplitude, while at the same time the amplitude of the $\mathrm{Cu}-\mathrm{Cu}$ peak of the underlying metal substrate at $\sim 2.2 \AA$ radial distance is too large.

Thus one important conclusion from the present study is that several different incidence angles below, at and above the critical angle of total reflection must be considered for a meaningful reflection-mode EXAFS data evaluation in general. Furthermore, neglecting surface roughness leads to several smaller deviations between both simulations and the experiment. For example, for incidence angles exactly at the critical angle (i.e. $\Theta=0.30^{\circ}$ in Fig. 9) the metal contributions at $2.2 \AA$ radial distance are underestimated by about $6-7 \%$, while the peak intensity for larger incidence angles shows an antipodal behaviour, i.e. the simulation suggests a significantly larger amplitude compared with the experiment and the simulation which includes roughness effects. It has to be stressed that these observations are a proof of the importance and significance of surface and interface roughness for grazing-incidence X-ray absorption spectroscopy.

\section{Conclusion and outlook}

The influence of surface and interface roughness parameters on reflection-mode EXAFS spectra from layered systems has been investigated in detail. Those situations where the X-ray absorbing element is present in more than one of the layers, or in the layer and the substrate, are especially considered. It can be concluded that surface and interface roughness is an important parameter for any quantitative reflection-mode EXAFS data analysis. Only in the case of smooth surfaces revealing a roughness $\sigma$ below $10 \AA$ are the changes introduced in the reflection-mode XAFS data of minor importance; however, even in these cases it should be considered whether precise results are expected from the experiments. With increasing surface and interface roughness, an increasing influence of $\sigma$ on the resulting fine-structure data was found, and a non-consideration of roughness may lead to erroneous results in terms of the coordination numbers or disorder parameters of the respective species, or the thickness of the related layers. In general, thus, for the detailed modelling of experimental reflection-mode EXAFS data a huge number of parameters (bond distances, coordination numbers, disorder parameters, layer thicknesses, roughness parameters etc.) may be required (see also Benzi et al., 2008), which in particular may render the practical data analysis rather difficult, even in the case of a rather simple sample system such as the oxidized copper surfaces treated in the present contribution. Anyhow, the number of free parameters can be reduced by assigning the morphological parameters of the layer structure by means of the analysis of the reflectivity at a fixed energy or, even better, by a simultaneous fit of X-ray reflectometry data and the reflection-mode XAFS spectra. It should be noticed that such a procedure has also recently been successfully introduced to magnetic soft X-ray scattering (e.g. Tonnerre et al., 2008).

In parallel, however, the results presented here have demonstrated that it is generally required to measure reflection-mode EXAFS data of layered sample systems for several grazing angles below, at and above the critical angle of total reflection, and those data have to be modelled consistently with one single set of parameters. This procedure consolidates the obtained results significantly and thus, in the light of the results presented here, the impact of reflection-mode X-ray absorption spectroscopy for future experiments should be ensured. 
We would like to thank U. Haake, D. Novikov and K. Bruder for their manifold help at the beamlines during the experiments and many exciting discussions. The provision of beam time at the DORIS III storage ring and the financial support of the experiments by HASYLAB are gratefully acknowledged.

\section{References}

d'Acapito, F., Castrucci, P., Pinto, N., Gunella, R., de Crescenzi, M. \& Davoli, I. (2002). Surf. Sci. 518, 183-191.

d'Acapito, F., Fratoddi, I., d'Amato, R., Russo, M. V., Contini, G., Davoli, I., Mobilio, S. \& Polzonetti, G. (2004). Sensors Actuators B, 100, 131-134.

Ankudinov, A. L., Ravel, B., Rehr, J. J. \& Conradson, S. D. (1998). Phys. Rev. B, 58, 7565-7576.

Apen, E., Rogers, B. R. \& Sellers, J. A. (1998). J. Vac. Sci. Technol. A, 16, 1227-1232.

Barr, T. L. (1994). Modern Esca. Boca Raton: CRC Press.

Benzi, F., Davoli, I., Rovezzi, M. \& d'Acapito, F. (2008). Rev. Sci. Instrum. 79, 103902.

Boer, D. K. G. de (1996). Phys. Rev. B, 53, 6048-6064.

Boer, D. K. G. de \& Leenaers, A. J. G. (1996). Physica B, 221, 18-26.

Born, M. \& Wolf, W. (1975). Principles of Optics, 5th ed. Oxford: Pergamon.

Borthen, P. \& Strehblow, H.-H. (1993). Thin Solid Films, 226, 161163.

Borthen, P. \& Strehblow, H.-H. (1995). Phys. Rev. B, 52, 3017-3019.

Borthen, P. \& Strehblow, H.-H. (1997). J. Phys. IV (France), 7(C2), 187-189.

Bosio, L., Cortes, R., Delichère, P., Froment, M. \& Joiret, S. (1988). Surf. Interface Anal. 12, 380-384.

Charnock, J. M., England, K. E. R., Farquhar, M. L. \& Vaughan, D. L. (1995). Physica B, 208-209, 457-458.

Cheong, S., Bunker, B., Hall, D. C., Snider, G. L. \& Barrios, P. J. (2001). J. Synchrotron Rad. 8, 824-826.

Cortes, R., Froment, M., Hugot-LeGoff, A. \& Joiret, S. (1990). Corros. Sci. 31, 121-127.

Cross, J. O., Newville, M., Rehr, J. J., Sorensen, L. B., Bouldin, C. E., Watson, G., Gouder, T., Lander, G. H. \& Bell, M. I. (1998). Phys. Rev. B, 58, 11215-11225.

Davenport, A. J. \& Sansone, M. (1995). J. Electrochem. Soc. 142, 725730.

Filatova, E., Lukyanov, V., Barchewitz, R., André, J.-M., Idir, M. \& Stemmler, P. (1999). J. Phys. Condens. Matter, 11, 3355-3370.

Frankenthal, R. P. (1990). Corros. Sci. 31, 59-68.

Gibson, P. N. \& Crabb, T. A. (1995). Nucl. Instrum. Methods Phys. Res. B, 97, 495-498.

Grenier, S., Proietti, M. G., Renevier, H., Gonzalez, L., García, J. M., Gérard, J. M. \& García, J. (2001). J. Synchrotron Rad. 8, 536-538.

Heald, S. M., Chen, H. \& Tranquada, J. M. (1988). Phys. Rev. B, 38, 1016-1026.

Hecht, D., Borthen, P. \& Strehblow, H.-H. (1996). Surf. Sci. 365, $263-$ 277.

Hecht, D., Frahm, R. \& Strehblow, H.-H. (1996). J. Phys. Chem. Lett. 100, 10831-10833.

Henke, B. L., Gullikson, E. M. \& Davis, J. C. (1993). Atom. Data Nucl. Data Tables, 54, 181-342.
Hóly, V. \& Baumbach, T. (1994). Phys. Rev. B, 49, 10668-10676.

Iijima, J., Lim, J.-W., Hong, S.-H., Suzuki, S., Mimura, K. \& Isshiki, M. (2006). Appl. Surf. Sci. 253, 2825-2829.

Jiang, D. T. \& Crozier, E. D. (1997). J. Phys. IV (France), 7(C2), 247249.

Jiang, D. T., Crozier, E. D. \& Heinrich, B. (1991). Phys. Rev. B, 44, 6401-6409.

Keil, P., Lützenkirchen-Hecht, D. \& Frahm, R. (2005a). Europhys. Lett. 71, 77-83.

Keil, P., Lützenkirchen-Hecht, D. \& Frahm, R. (2005b). Phys. Scr. T115, 246-248.

Koetter, T. G., Wendrock, H., Schuehrer, H., Wenzel, C. \& Wentzig, K. (2000). Microelectron. Reliab. 40, 1295-1299.

Król, A., Sher, C. J. \& Kao, Y. H. (1988). Phys. Rev. B, 38, 8579 8592.

Lenglet, M., Kartouni, K., Machefert, J., Claude, J. M., Steinmetz, P., Beauprez, E., Heinrich, J. \& Celati, N. (1995). Mater. Res. Bull. 30, 393-403.

Lohrengel, M. M., Schultze, J. W., Speckmann, H.-D. \& Strehblow, H.-H. (1987). Electrochim. Acta, 33, 733-742.

Luo, G. M., Mai, Z. H., Hase, T. P. A., Fulthorpe, B. D., Tanner, B. K., Marrows, C. H. \& Hickey, B. J. (2001). Phys. Rev. B, 64, 245404.

Lützenkirchen-Hecht, D. \& Frahm, R. (2001). J. Synchrotron Rad. 8, 478-480.

Lützenkirchen-Hecht, D. \& Frahm, R. (2005). Physica B, 357, $213-$ 217.

Lützenkirchen-Hecht, D. \& Frahm, R. (2006). Surf. Sci. 600, 43804384.

Lützenkirchen-Hecht, D., Wagemaker, M., Keil, P., van Well, A. A. \& Frahm, R. (2003). Surf. Sci. 538, 10-22.

Martens, G. \& Rabe, P. (1980). Phys. Status Solidi A, 58, 415-424.

Melendres, C. A., Bowmaker, G. A., Leger, J. M. \& Beden, B. J. (1998). J. Electroanal. Chem. 449, 215-218.

Millet, B., Fiaud, C., Hinnen, C. \& Sutter, E. M. M. (1995). Corros. Sci. 37, 1903-1918.

Névot, L. \& Croce, P. (1980). Rev. Phys. Appl. 15, 761-780.

Palasantzas, G. (1993). Phys. Rev. B, 48, 14472-14478.

Parratt, L. G. (1954). Phys. Rev. 95, 359-369.

Ravel, B. \& Newville, M. (2005). J. Synchrotron Rad. 12, 537-541.

Ressler, T. (1998). J. Synchrotron Rad. 5, 118-122.

Schmuki, P., Virtanen, S., Davenport, A. J. \& Vitus, C. M. (1996). J. Electrochem. Soc. 143, 3997-4005.

Sinha, S. K., Sirota, E. B., Garoff, S. \& Stanley, H. B. (1988). Phys. Rev. B, 38, 2297-2311.

Strehblow, H.-H. \& Titze, B. (1980). Electrochim. Acta, 25, 839850.

Tolan, M. (1999). X-ray Scattering from Soft Matter Thin Films, Springer Tracts in Modern Physics, Vol. 148. Berlin: Springer.

Tonnerre, J. M., De Santis, M., Grenier, S., Tolentino, H. C. N., Langlais, V., Bontempi, E., García-Fernández, M. \& Staub, U. (2008). Phys. Rev. Lett. 100, 157202.

Wagemaker, M., Lützenkirchen-Hecht, D., van Well, A. A. \& Frahm, R. (2004). J. Phys. Chem. B, 108, 12456-12464.

Yang, J. C., Kolasa, D., Gibson, J. M. \& Yeadon, M. (1998). Appl. Phys. Lett. 73, 2841-2843.

You, H., Melendres, C. A., Nagy, Z., Maroni, V. A., Yun, W. \& Roncon, R. M. (1992). Phys. Rev. B, 45, 11288-11298.

Zheng, S., Hayakawa, S. \& Gohshi, Y. (1997). J. Electron Spectrosc. Relat. Phenom. 87, 81-89. 